\title{
Effect of permeability on GFRP laminate produced by VARTM process
}

\author{
Bairoju Shankarachary ${ }^{1 *}, N$ Sateesh $^{2}$, Lavu Gopinath $^{l}$, and Siripuram Aparna ${ }^{l}$ \\ ${ }^{1}$ Assistant Professor, Department of Mechanical Engineering, Gokaraju Rangaraju Institute of Engineering and Technology, Hyderabad, \\ India \\ ${ }^{2}$ Professor \& HoD, Department of Mechanical Engineering, Gokaraju Rangaraju Institute of Engineering and Technology, Hyderabad, \\ India
}

\begin{abstract}
Vacuum assisted resin transfer molding (VARTM) is one of the manufacturing technique that is viable for production of fiber reinforced polymer composite components suitable for aerospace, marine and commercial applications. However the repeatable quality of the product can be achieved by critically fixing the process parameters such as Vacuum Pressure (VP) and permeability of the preform. The present investigation is aimed at studying the effect of permeability for production of Glass Fiber Reinforced Polyester (GFRP) components with consistent quality. The VARTM mould is made with an acrylic transparent top cover to observe and record the resin flow pattern. Six layers of randomly placed glass fiber under five different vacuum pressures VP1 $=0.013, \mathrm{VP} 2=0.026, \mathrm{VP} 3=0.039, \mathrm{VP} 4=0.053$ and VP5 $=$ $0.066 \mathrm{MPa}$ were studied. The laminates produced by this process under the above mentioned conditions were characterized with ASTM D procedures so as to study the effect of these process parameters on the quality of the laminate. And as mentioned there is a considerable effect of permeability on the impact strength and the void content in the laminates under different vacuum pressures. SEM analysis of the impact tested fractured GFRP composites showed the bonding of fiber and matrix.
\end{abstract}

Keywords: Permeability; VARTM; ASTM D Standards; SEM.

\section{Introduction}

In aerospace industry, a conventional manufacturing method like auto clave process is replaced because of high quality laminates produced by VARTM process [1]. In VARTM process for accurate process model and resin flow, permeability of fiber preform is the key parameter that as to be determined experimentally [2-3]. An experimental set up was fabricated to determine permeability by varying volume fraction of fiber [4].Flow visualization study was used to measure permeability [5]. An empirical model, prediction method was established to estimate permeability. However, for all numerical simulations, valid permeability is obtained from experimental test than the theoretical predictions [6-7]. The continuous random fiber mat has higher permeability than bi-directional woven fabric for the same fiber volume fraction [8]. Permeability of Fiber bed was measured noted that lowest for carbon mats. Hence injection cycle will be much longer, because of which parts manufactured using of carbon fiber mats in comparison with either chopped or woven fiberglass mats with the same porosity or fiber content [9].The application of vacuum pressure in RTM process removes moisture and other contaminates which increase the quality of the laminate [10]. the reduction of void content to $2 \%$ or less is the greatest challenge faced in ht-VARTM as it is required for aerospace applications and it done by various process modifications, the maximum vacuum pressure will minimize the voids and will effect the quality of the laminate [11-14]. The woven keneaf /epoxy composite impact strength is superior and interfacial adhesion of fiber and matrix is observed from the SEM analysis [15].

\section{Experimentation}

\subsection{Laminate preparation produced by VARTM}

An alternative development to the conventional RTM process is Vacuum Assisted Resin Transfer Molding (VARTM), the complexities linked with design of large metal tooling and cost are reduced. mould upper half of the VARTM process is replaced by a vacuum bag, so we can eliminate an accurate matched metal mold as in the conventional RTM process. In the starting of process, we need to start with expelling air from the preform assembly using a vacuum pump and it will continue upto equilibrate the system means that the air leaks have been eliminated. Then resin is allowed to flow into the perform under the atmospheric pressure. The advantage with this is provides the driving force for the resin to impregnate the reinforcement and the compression force to compact the preform to the desired fiber volume fraction together. The quality of the final component depends on various parameters out of which the location of resin injection and vacuum ports, the perform pattern and injection pressure are main parameters. In the present study an aluminum mould of $0.4 \mathrm{X} 0.4 \mathrm{~m}$ was milled to create a pocket of $0.005 \mathrm{~m}$. The upper mould is made from a $0.02 \mathrm{~m}$ thick acrylic sheet with a

\footnotetext{
*Corresponding author: sateeshnagari1@gmail.com
} 
provision for inlet ports on the top. The ports are placed on to the diagonal of the square upper half, a rubber oring on the mould prevents the air leak and provides a perfect vacuum. The two half's of the mould were cleaned and coated with mould relishing agent and six layer performs of chopped strand glass mats 450 GSM were stacked in the mould cavity. The mould was then evacuated with entrapped air form the two end diagonals of the upper mould and as said above left to equilibrate, later the general purpose polyester resin is allowed to pass from the center port until the mould is completely filled. The flow front of resin is recorded in web camera mounted on the top of the mould. The mould is allowed for curing under room temperature and samples of required geometry were cut form the laminate prepared. The same process was repeated for 6 layers of pre forms with different inlet vacuum pressures from VP1 to VP5.

Fig. 1. The schematic diagram of VARTM experimental set up

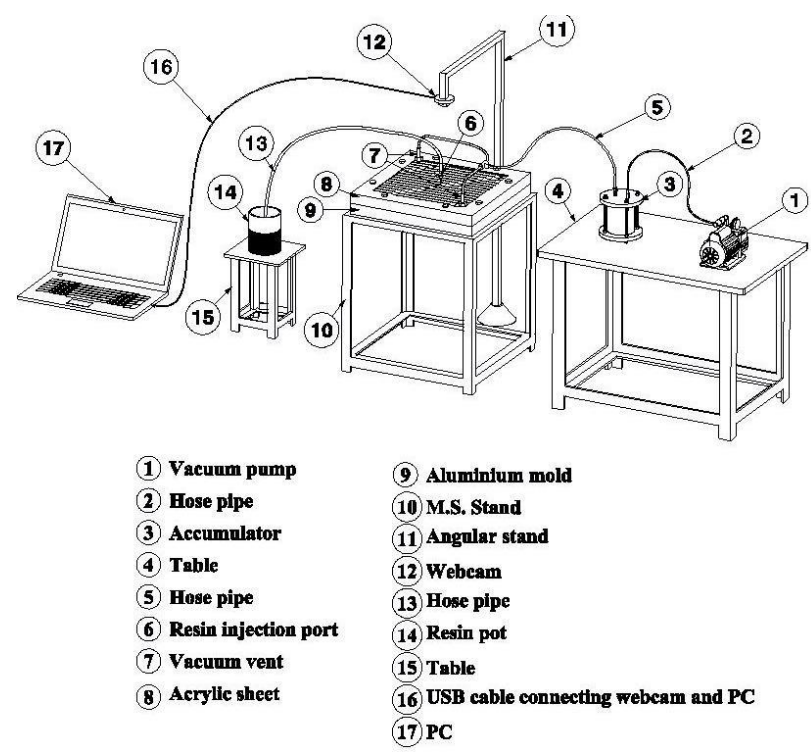

\subsection{Determination of permeability of fiber perform}

To maintien constant vacuum pressure, the resin inlet kept at the middle of the mould, Bryan M. Louis et al [6] calculated the permeability by using below equations

$$
K=\frac{\mathrm{Q} \cdot \eta \cdot \ln \left(\mathrm{r}_{\mathrm{f}} / \mathrm{r}_{\mathrm{i}}\right) \cdot \mathrm{r}_{\mathrm{i}}^{2}}{\mathrm{~A} \cdot \mathrm{P}}
$$

Where $\mathrm{Q}$ is the constant volumetric flow rate, preform permeability $\mathrm{K}$ can be determined by knowing the size of radial flow front $r_{\mathrm{f}}$, size of the initial injection radius $r_{i}$, viscosity of resin $\eta_{\text {,cross sectional }}$ area of the preform $\mathrm{A}$, resin injection pressure $\mathrm{P}$.

$$
r_{f}=\sqrt{\frac{Q}{\varepsilon \cdot \pi \cdot h} \cdot t+r_{i}^{2}}
$$

Where $\epsilon$ represents Porosity, $\mathrm{h}$ is the cavity height of the mold, $t$ is the filling time determined by image processing technique are used to calculate $r_{f}$.

The Carman-Kozeny relation is used to determine the porosity. The porosity $(\varepsilon)$ value is the percentage of pores inside preform, i.e.

$$
\varepsilon=1-\frac{\text { fiber volume in cavity }}{\text { cavity volume }}
$$

\subsection{Determination of void content as per ASTM D 2734-94 standards}

VARTM impact test specimens were produced by varying vacuum pressure, as mentioned in the laminate preparation process. Flow pattern of resin through the preform is changed with respect to change in the the vacuum pressure that means the flow front velocity through the preform is increasing with the vacuum pressure for a given reinforcement volume fraction. Voids will be formed in the cured composite laminate. Because of the flow characteristics of resin are changing with resin vacuum pressure. ASTM D 2734-94 standard procedure is followed to assess the void content on the laminate. The same technique is used to find void content .The mathematical expression for void content is furnished in the following equation

$$
V=100-M_{d}\left(\frac{r}{d_{r}}+\frac{g}{d_{g}}\right)
$$

Where $\mathrm{V}=$ void content (volume $\%$ ), $\mathrm{Md}=$ measured density, $r=$ resin (weight $\%$ ), g=glass (weight $\%$ ), $d r=$ density of resin, $\mathrm{dg}=$ density of glass. The laminates produced are trimmed to a known dimension $0.3 \mathrm{~m}$ $\mathrm{x} 0.3 \mathrm{~m}$ to remove excess resin and above mentioned formulae is utilized to calculate void concentration

\subsection{Izod impact test}

The prepared glass fiber reinforced composite lamina with 6 layers at $\mathrm{VP}_{1}, \mathrm{VP}_{2}, \mathrm{VP}_{3}, \mathrm{VP}_{4}$ and $\mathrm{VP}_{5}$ vacuum pressures are machined to prepare the samples according to ASTMD 256 for Izod impact test. The sample of Izod impact test machined specimens was shown in Fig. 2

The notch of $2.5 \mathrm{~mm}$ depth is cut carefully on the composite specimens. Notch cut specimen is fixed firmly by the facing the notch towards striking end of the Izod impact tester, IZC22 Model, for the Izod impact test five specimens are tested and its average value is considered 
for the determination of composites mechanical properties.

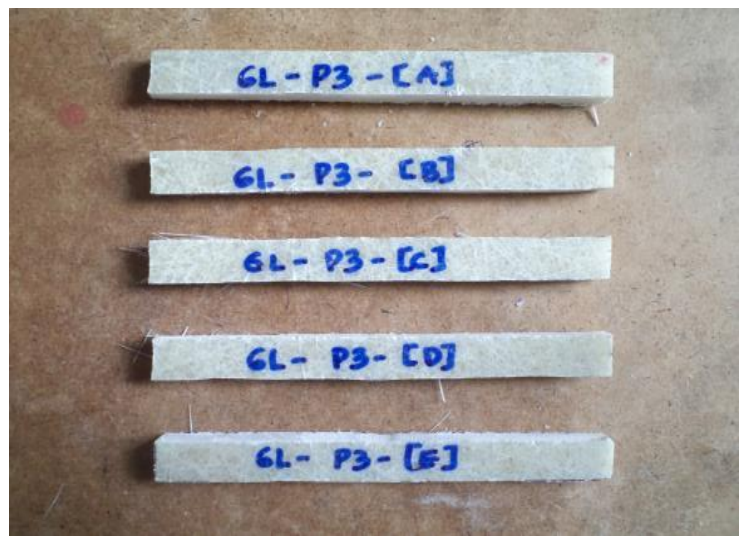

Fig.2. Specimens of Six Layers Chopped Strand Mat Glass Fiber Polyester Resin Laminate as Per Specifications of ASTM D 256.( Ref.22)

\subsection{SEM analysis}

Glass fiber reinforced polyester composite specimens after their impact testing are subjected to scanning electron microscope analysis for better understanding the nature of bonding between reinforcement and matrix. In order to get the clarified image of the fractured sample, it is sputtered with gold. Izod impact and SEM tests are conducted at Kelvn Labs Telangana, India.

\section{Results and discussions}

\subsection{Permeability of chopped strand MAT glass fiber}

Changes in permeability, voids volume percent against increase in vacuum pressure were drawn in Fig.3. The permeability of resin mixture and voids volume percent obviously increased with increase in vacuum pressure from $\mathrm{VP}_{1}$ to $\mathrm{VP}_{5}$ in the cases of the composites experimentally studied in this work. The highest permeability of $0.000280 \mathrm{~m}^{2}$ was observed in case of the composites reinforced with vacuum pressure $\mathrm{VP}_{5}$

Y. J. Lee et al. [2] prepared plane woven glass fiber reinforced polyester composite of $1,2,4,8,12$ and 16 layers composites by cutting the preform of $50 \times 15 \mathrm{~cm}$ long and placed in the mold then the peel ply, resin distribution layer and vacuum bag were placed and inlet runner channel connection is given to the polyester resin container and outlet is connected to the vacuum pot and vacuum pump. The resin injection port was at end center and flow of resin was recorded by video camera and determined permeability from the equation derived from Darcy's law and obtained permeability value for 4 and 8 layers $8 \times \mathrm{E}-10$ and $6 \times \mathrm{E}-10 \mathrm{~m}^{2}$. This is lesser than the obtained value of this experimental work. The reason is due to resin propagation from one end center and vacuum bagging used in their work.
N.C. Correia et al. [16] in their review on vacuum infusion and its effect on permeability analyzed that with the increase in vacuum from vent the permeability of the fiber preform were altered and in comparison the same analysis were observed from the results obtained in present work.

\subsection{Void content}

According to ASTMD 2734, Method B the void content in glass fiber reinforced polyester composites was determined from the experimental results. Then the graph is drawn between vacuum pressure, percentage of void content for 6 layer of chopped strand mat already shown in Fig.3 \& Fig.4 The void volume (\%) is increased with the increase in vacuum pressure and low void volume percent (3.39) is observed for vacuum pressure VP1.

Vishwanath R. Kedari et al [13] fabricated aluminum mold of $30 \times 30 \mathrm{~cm} \mathrm{,} 2$ to 3 layers of mold release is applied and E-glass chopped strand mat of areal density $457.5 \mathrm{~g} / \mathrm{m} 2$ is taken and placed in the mold. A peel ply and layer of distribution medium are placed on the top of the preform. An unsaturated polyester resin is used and inflow helical tube is connected to the resin container and the mold. Whereas the out flow is connected to the vacuum pump and calculated void content as per ASTM D 2734 standards. From their work it is found that when vacuum pressures was increasing from 0.649 to 1.013 bar the voids volume percent was increased from 0.21 to $0.36 \%$. However the same trend was observed in our experimental study, when the vacuum pressure was increasing from 0.013 to $0.066 \mathrm{MPa}$, the voids volume \% was increased from 3.39 to $36.91 \%$ for constant number of stacks.

\subsection{Impact strength}

Izod impact strength of glass fiber reinforced polyester composite specimens was determined and graphically shown in Fig.4 \& Fig.5 Highest impact strength 113 $\mathrm{KJ} / \mathrm{m}^{2}$ was shown at $\mathrm{VP} 1$.

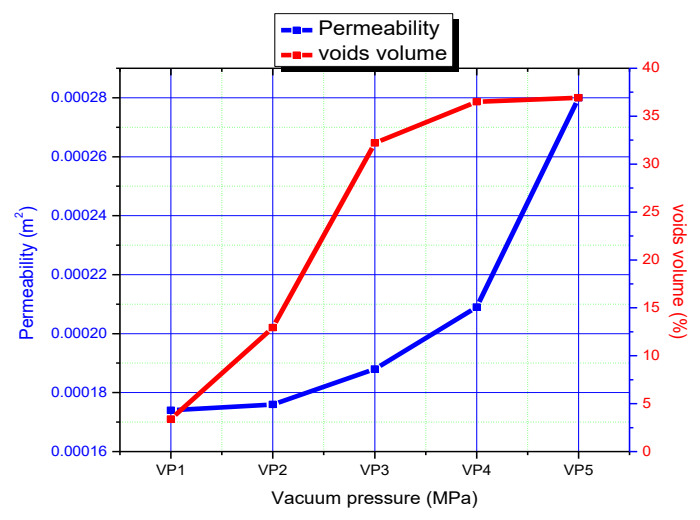

Fig..3.Vacuum pressure v/s permeability, voids vol \%

Chopped strand E-glass fiber with an areal density of 450 GSM was reinforced into Lapox-L12 and Lapox K6 epoxy resin system and hardener respectively by VARIM 
process to prepare a composite panel of $300 \mathrm{~mm} \times 300$ $\mathrm{mm}$ with the above experimental conditions, Srinivas Shenoy Heckadka et al. [18], reported that for the 3 layers of the glass fiber epoxy composites exhibited an impact strength of about $104 \mathrm{KJ} / \mathrm{m}^{2}$. The Izod impact strength achieved in this work is $113 \mathrm{KJ} / \mathrm{m}^{2}$ for 6 layers The reasons for the decrease in impact strength are i)Vacuum bagging, ii) vacuum pressures, iii) method of injection of resin i.e. distribution of resin mixture from center to all sides and corners of the mould.

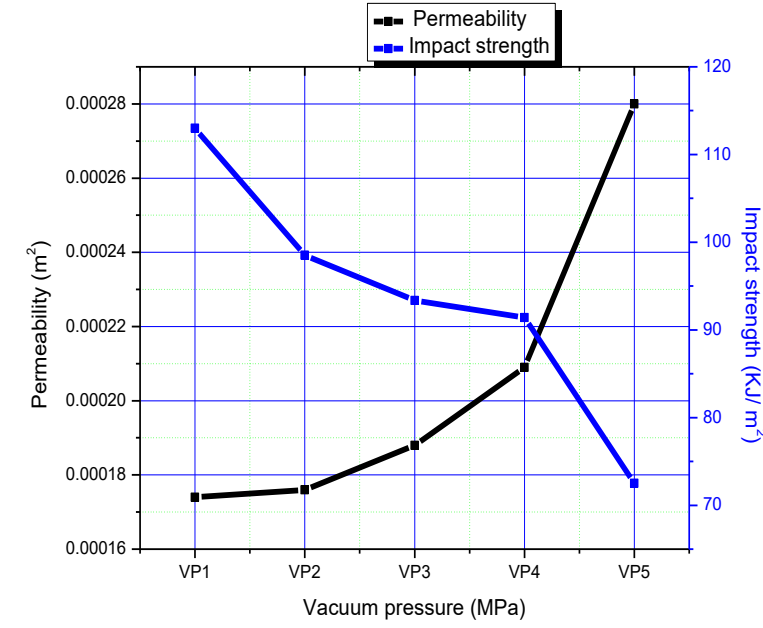

Fig. 4. Vacuum pressure v/s permeability, impact strength

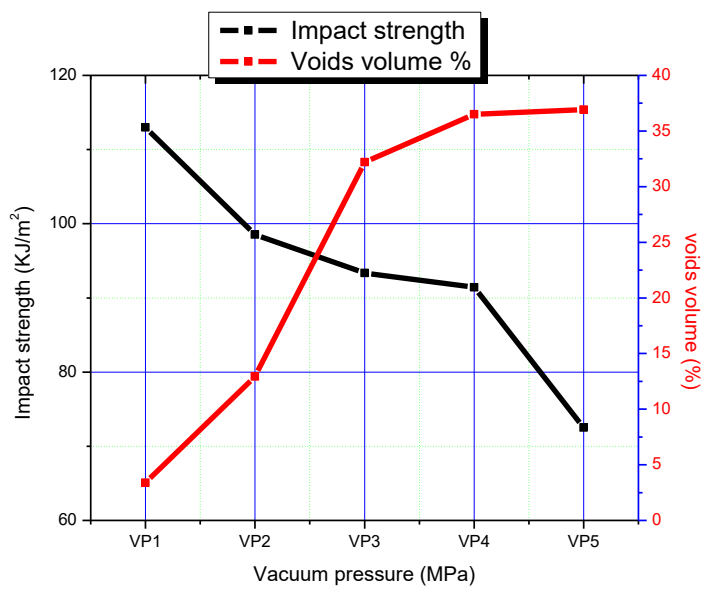

Fig. 5. Vacuum pressure v/s impact strength, voids vol $\%$

\subsection{Scanning electron microscopic study of composites}

Using scanning electron microscope Izod impact tested glass fiber reinforced composite specimens was analyzed for their bonding characteristics and observed the fiber displacement due to nonlinear flow of resin and bending of fiber in Fig.6 and Fig.7.

Srinivas Shenoy Heckadka et al. [18] reported that plain weave glass fiber reinforced polyester composites exhibited fiber pullout. Fiber pullout from the matrix was also observed in the present experimental work.

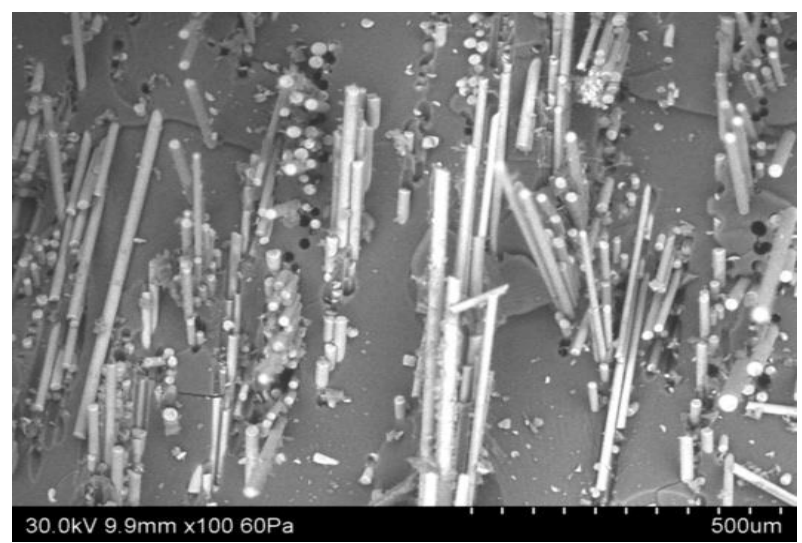

Fig. 6. SEM Images of Izod impact test specimen indicating fiber pull out.

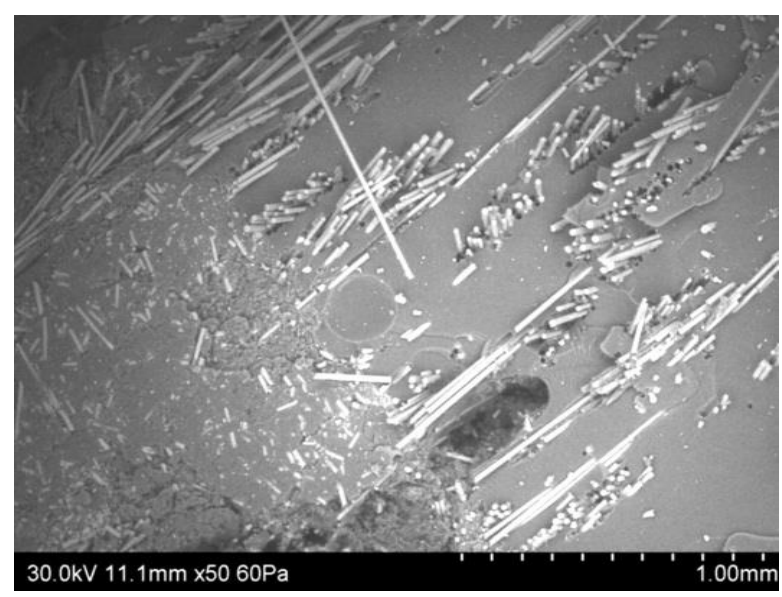

Fig. 7. SEM Images of Izod impact test specimen indicating matrix domination over fiber.

\section{Conclusions}

The predetermined amount of vacuum pressure was measured before the resin enters into the mold. So, the VARTM experimental set up used in this work was helpful in successful preparation of CSM GFRP composite laminate at different vacuum pressures. An increase in vacuum pressure was responsible for the increase in permeability of the preform from 0.000174 to $0.000280 \mathrm{~m} 2$ corresponds to the vacuum pressure from 0.013 to $0.066 \mathrm{MPa}$. The low void volume percent $(3.39 \%)$ is observed for vacuum pressure (VP1), voids volume percent can be further decreased even for increasing the vacuum pressures by degassing resin and burn off resin concluded by T.Stafffan Lundstrom et al [19]. The decrease in voids content will increase the quality of laminate. The highest izod impact strength of GFRP composite is $113 \mathrm{KJ} / \mathrm{m} 2$ was obtained for $0.000174 \mathrm{~m} 2$ permeability, void volume percent $(3.39 \%)$ and 0.013 vacuum pressure (VP1). SEM images of izod impact tested specimens represented that the domination of matrix over the fiber, fiber pull out behavior in GFRP composites. 


\section{References}

1. Li, W., Krehl, J., Gillespie, J.W., and Helder, D., 2004, "Process evaluation of the vacuum assisted process." Journal of Composite Materials, 38 (20), pp. $1803-1814$.

2. Lee, Y.J., Wu, J.H., and Hsu, Y., 2006, “A prediction method on in - plane permeability of mat / roving fiber laminates in vacuum assisted resin transfer molding." Journal of Polymer Composites, pp. 665 670.

3. Antonucci, V., Esposito, M., Ricciardi, M.R., Raffane, M., Zarrelli, M., and Giordano, M., 2011, "Permeability characterization of stitched carbon fiber preforms by fiber optic sensors." Express Polymer Letters, 12, pp. $1075-1084$.

4. Xludong Sun, Shoujie Li, and James Lee, L., 1998, "Mold filling analysis in vacuum assisted resin transfer molding part 1: SCRIMP based on a high permeable medium." Journal of Polymer Composites, 19(6), pp. $807-817$.

5. Chensong Dong and Tuong Yung Tang., 2010, "A generic model of predicting permeability of fiber mats." Journal of Advanced Materials Research, 123, pp. $515-518$.

6. Bryan Louis, M., Claudio Di Fratta, Mario Danzi, Dr. Markus Zogg and Prof. Dr. Paoloermanni, 2011, "Improving time effective and robust techniques for measuring in plane permeability of fibre performs for $1 \mathrm{~cm}$ processing." SEICO11- 32nd International conference -New Material Characteristics to cover New Application Needs session Paris, 3A, pp. 204211.

7. Min Li, Shao- Kai Wang, Yi - Zhuo Gu, Yan - Xia Li, Kevin Potter, and Zuo - Guang Zhang., 2012, "Evaluation of through thickness permeability and the capillary effect in vacuum assisted liquid molding process." Journal of Composites Science and Technology, 72, pp. $873-878$.

8. Yulu Ma, Xiao bin Hu and Dongdi Wu., 1997, "The permeability of glass fiber mat and its influence on the filling time of R.T.M process. "Journal of Composites Processing Microstructure, Gold Coast Australia, pp. 19 - 26.

9. Hossein Golestanian., 2007, "Physical determination of permeability variation with porosity for composite performs." Journal of Engineering Science, Industrial \& Mechanical Engineering Special Issue, 18 (3-4), pp. 67-73.

10. Hayward, J.S., and Harris, B., 1990, "The effect of vacuum assistance in resin transfer moulding." Journal of Composites Manufacturing, 1(3), pp. 161 -166 .
11. Elias Riagas, J., Thomas Mulkern J., Shawn Walsh, M., and Steven Nguyen., P., 2001, "Effects of process conditions on vacuum assisted resin transfer molding process (VARTM)." ARL - TR - 2480, pp. $1-55$.

12. Dominik Bender, Jens Schuster, and Dirk Heider., 2006, "Flow rate control during vacuum assisted transfer molding (VARTM) processing." Journal of Composites Science and Technology, 66, pp. 2265 2271.

13. Vishwanath Kedari, R., Basil Farah, 1., and Kuang Ting Hsiao., 2011, "Effects of vacuum pressure, inlet pressure, and mold temperature on the void content, volume fraction of polyester / E- glass fiber composites manufactured with VARTM process." Journal of Composite Materials, 45 (26), pp. 2727 2742.

14. K Ghose, S., Cano, R. J., Britton, S.M., Watson, A., Jensen, B.J., and Connell, J. W., 2011, "High temperature VARTM of phenylethynyl terminated imide (PETI) resins." SAMPE Journal, 47 (22), pp. 6 -15 .

15. Suhad Salman, D., Moharman Sharba, J., Leman, Z., Sultan, M.T.H., Ishak, M.R., and Cardona, F., 2015, "Physical, mechanical, and morphological properties of woven kenaf/ polymer composites produced using a vacuum infusion technique.” International Journal of Polymer Science, 2015, pp. 1 - 10.

16. Correia, N.C., Robitaille, F., Long, A.C., Rudd, C.D., Simacek, P., and Advani, S.G., 2005, "Analysis of the vacuum infusion moulding process: 1. Analytical formulation." Journal of Composites Part A, 36, pp. $1645-1656$.

17. Govignon, Q., Bickerton, S., and Kelly, P.A., 2012, "Experimental investigation into the post - filling stage of the resin infusion process." Journal of Composite Materials, 47 (12), pp. 1479 - 1492.

18. Srinivas Shenoy Heckadka, Suhas Yeshwant Nayak, Karan Narang and Kirti Vardhan Pant., 2015, "Chopped strand/plain weave e-glass as reinforcement in vacuum bagged epoxy composites." International journal of materials, 2015, pp. 1 - 7.

19. Staffan Lundstorm, S., and Rikard Gebart, B., 1994, "Influence from process parameters on void formation in resin transfer molding." Journal of Polymer Composites, 15(1), pp. 25 - 33.

20. Kundavarapu Vengalrao, Kopparthi Phaneendra Kumar, Dasari Venkata Ravi Shanker, Nadendla Srinivasababu, Aerra Kiran Kumar Yadav. "An investigation on the Quality of the Laminates Produced by VARTM Process and Process parameters", Materials Today: Proceedings, 2017. 